\title{
PERANCANGAN ALAT DETEKSI KEBOCORAN GAS PADA PERANGKAT MOBILE ANDROID DENGAN SENSOR MQ-2
}

\author{
Ajeng Savitri Puspaningrum*,1), Fadli Firdaus'), Imam Ahmad ${ }^{3)}$, Harry Anggono4) \\ ${ }^{1,2)}$ Program Studi Teknik Komputer, Fakultas Teknik dan Ilmu Komputer, Universitas Teknokrat Indonesia \\ Jl. ZA. Pagar Alam No.9 -11, Labuhan Ratu, Bandar Lampung, Indonesia 35132 \\ ${ }^{3,4)}$ Program Studi Informatika, Fakultas Teknik dan Ilmu Komputer, Universitas Teknokrat Indonesia \\ Jl. ZA. Pagar Alam No.9 -11, Labuhan Ratu, Bandar Lampung, Indonesia 35132 \\ Email: 1ajeng.savitri@teknokrat.ac.id
}

\begin{abstract}
The role of LPG gas at this time is very for human life both at home and in industry. However, gas can have a negative impact, especially if there is no known leakage from the cylinder or LPG gas storage area. The cause of this leakage of gas cylinders can occur due to leaks in hoses, tubes or regulators that are not properly installed and the gas cylinders that are distributed are of poor quality or physically damaged. This study aims to produce a design of gas leak detection devices on Android mobile devices with the MQ-2 sensor as a gas sensor, and the Ethernet shield as a module on the microcontroller to connect Arduino to the internet network. The way this tool works, when the MQ-2 sensor detects LPG gas, the sensor will send data to the microcontroller to be given a response in the form of turning on the fan, buzzer as an alarm, and this tool can send analog gas data information to the Android smartphone using the Cayenne plaltform via the internet network.
\end{abstract}

Keywords: Microcontroller, MQ-2 Sensor, Exhaust Fan, LPG Gas, IoT

\section{Abstrak}

Peranan gas LPG pada saat ini sangatlah penting bagi kehidupan manusia baik di rumah tangga maupun di industri. Namun, gas dapat berdampak negatif, terutama bila tidak diketahui telah terjadi kebocoran dari tabung atau tempat penyimpanan gas LPG tersebut. Penyebab dari bocor tabung gas ini bisa terjadi karena kebocoran pada selang, tabung atau pada regulatornya yang tidak terpasang dengan baik dan tabung gas yang didistribusikan memang kualitasnya kurang baik atau rusak fisik. Penelitian ini bertujuan untuk menghasilkan sebuah perancangan alat deteksi kebocoran gas pada perangkat mobile android dengan sensor MQ-2 sebagai sensor gas, dan ethernet shield sebagai modul pada mikrokontroler untuk menghubungkan arduino dengan jaringan internet. Cara kerja alat ini yaitu, ketika sensor MQ-2 mendeteksi gas LPG maka sensor akan mengirimkan data ke mikrokontroler untuk diberikan respon berupa menyalakan kipas, buzzer sebagai alarm, dan alat ini dapat mengirimkan informasi data analog gas ke smartphone android mengguna- kan plaltform Cayenne melalui jaringan internet.

Kata Kunci: Microcontroller, MQ-2 Sensor, Exhaust Fan, LPG Gas, IoT

\section{Pendahuluan}

Gas adalah suatu fase benda dalam ikatan molekul yang sangat renggang pada suhu tertentu. Gas mempunyai kemampuan untuk mengalir dan dapat berubah bentuk. Namun berbeda dari cairan yang mengisi pada besaran volume tertentu, gas selalu mengisi suatu volume ruang, mereka mengembang dan mengisi ruang di manapun mereka berada Bahan bakar dengan wujud gas ini mempunyai efek negatif, yaitu apa bila menguap di udara bebas akan membentuk lapisan dikarenakan kondensasi. Lapisan yang terbentuk ini bersifat mudah terbakar, sehingga sangat berbahaya apabila terjadi penumpukan di dalam ruangan tertutup dan berpotensi terjadi kebakaran. Gas LPG merupakan salah satu kebutuhan yang diperlukan dalam kehidupan sehari -hari khusus nya dalam rumah tangga, gas LPG dalam rumah tangga dimanfaatkan untuk memasak karna di zaman sekarang sudah tidak menggunakan lagi kayu bakar ataupun minyak bumi. Menggunakan gas LPG lebih berbahaya dari minyak bumi ataupun kayu bakar kebocoran terjadi karena beberapa faktor pemasangan yang kurang pas, pipa gas yang kendor dan pala tabung yang tidak sesuai dengan besarnya connector pipa sehingga terjadinya kebocoran.

Mengacu pada penelitian Ardy Rimanda Putra [1] yang berjudul "Aplikasi Monitoring Kebocoran Gas Berbasis Android Dan IOT dengan FireBase Realtime System" yang membahas tentang pendeteksi kebocoran gas LPG menggunakan mikrokontroler dimana penelitian tersebut menghasilkan sistem monitoring gas yand dapat mengetahui gas bocor atau tidak. Internet of Things IoT sendiri merupakan segala aktifitas yang pelakunya saling berinteraksi dan dilakukan dengan memanfaatkan internet sehingga dapat mempermudah pekerjaan manusia dengan memanfaatkan kemajuan teknologi [2][3]. Penerapan Internet of Things (IoT) juga dilaku-kan oleh Dias Prihatmoko [4] dimana penelitian yang dilakuknya menghasilkan sistem kontrol.

Menurut Casagras (Coordinator and support action for global RFID-related activites and standadisatuion), Internet of Things atau IoT didefinisikan sebagai sebuah 
infrastruktur jaringan global, yang menggabungkan benda - benda fisik dan virtual melalui eksploitasi, capture dan kemampuan komunikasi[5][6]. Penelitian ini dilakukan untuk melanjutkan penelitian [1] yaitu suatu alat pendeteksi kebocoran gas dengan menggunakan mikrokontroller yang dapat memonitoring adanya kebocoran gas yangdapat diamati secara langsung melalui smartphone android dan sensor MQ-2 sebagai modul sensor khusus untuk gas LPG dan modul ethernet shield arduino sebagai media transfer data dari mikrokontroler ke smartphone android melalui jaringan internet. Sistem ini dilengkapi dengan buzzer sebagai sirine dan informasi data analog yang nantinya akan tampil pada smartphone android. Penelitian ini juga menambahkan penangan terhadap sistem yang dibuat oleh [1] berupa exhaust fan dan relay listrik. Exhaust fan bekerja untuk menghisap udara (Gas) yang ada didalam ruangan tersebut untuk dibuang keluar ruangan sedangkan relay listrik untuk mematikan listrik apabila terjadi kebocoran gas agar tidak terjadinya kebakaran.

\section{Metodologi Penelitian}

Pengumpulan data penelitian ini dilakukan dengan beberapa metode yaitu :

1. Wawancara (Interview)

Metode ini dilakukan dengan cara tanya jawab secara langsung kepada Masyarakat atau pengguna Gas LPG. mengenai masalah yang dibahas pada tugas akhir

2. Pengamatan (Observation)

Dengan observasi penulis melakukan pengumpulan data penelitian dengan melihat alat sebelumnya yang telah dibuat dan penulis akan mengembangkan kekurangan alat tersebut sehingga penulis bisa menciptakan alat yang lebih sempurna dari alat yang telah dibuat sebelumnya.

3. Tinjauan Pustaka (Study literature)

Tinjauan pustaka merupakan kegiatan pengumpulan data dengan cara mencari buku-buku jurnal tugas akhir, buku-buku referensi, electronic book, maupun pencarian berbagai informasi data di internet yang berkaitan dengan penelitian agar bisa membantu penulis [7].

4. Eksperimen

Dengan metode ini penulis melakukan pengumpulan data dengan tahap pencobaan terhadap alat sehingga penulis bisa mengetahui apa saja yang harus dilakukan untuk perancangan alat ini.

\section{Analisis dan Perancangan}

\subsection{Skema diagram}

Skema diagram dari aplikasi monitoring gas LPG (Liquifed Petroleum Gas ) dapat dilihat pada gambar 1.

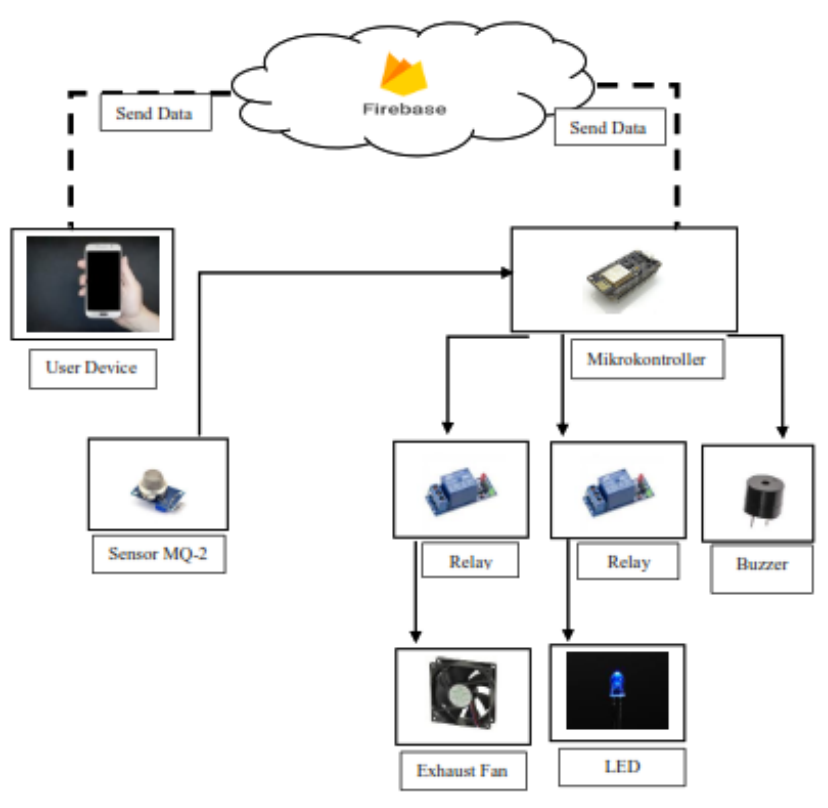

Gambar 1. Alur Kerja Sistem

Dari gambar alur kerja system, dapat diuraikan alur kerjanya sebagai berikut :

1. IoT ( Internet of Things )

Pada bagian IoT, Sistem berfungsi sebagai penghasil data pantauan gas LPG yang data patauanya didapat dari hasil pembacaan mikrokontroller lalu data akan dikirimkan ke realtime database firebase.

2. Cloud Database (firebase)

Berfungsi sebagai sarana komunikasi data antar perangkat, sehingga users dapat memantau tabung gas secara realtime

3. Smartphone

Berfungsi sebagai media monitoring yang akan dipasangkan aplikasi monitoring gas LPG yang telah dibuat. Dengan aplikasi ini user dapat dengan mudah mengetahui kondisi gas LPG. Informasi kondisi gas LPG akan ditampilkan dalam bentuk indicator pada smartphone android.

4. Mikrokontroller

Berfungsi sebagai pengontrol yang mengatur semua kinerja alat sekaligus sebagai wifi [8][9][10].

5. Relay $4 \mathrm{CH}$

Berfungsi untuk menggerakan sejumlah kontaktor yang tersusun atau sebuah saklar elektronis yang dapat dikendalikan dari rangkaian elektronik lainnya.

6. Power

Berfungsi untuk memberikan tegangan kepada NodeMCU dan Relay 4CH.

7. Buzzer

Berfungsi sebagai simulasi Alarm yang dapat mengeluarkan suara.

8. Fan DC

Berfungsi sebagai simulasi exhaust fan yang dapat membuang gas bila terjadi kebocoran.

9. LED ( Light-Emitting Diode )

Berfungsi sebagai simulasi Listrik yang menandakan bila terjadi bahaya listrik akan mati seketika. 


\subsection{Cara Kerja Alat}

Alat pendeteksi kebocoran gas dengan sistem monitoring berguna untuk mencegah dan mengurangi jika terjadi kebakaran/ledakan akibat gas yang keluar. Alat ini juga dapat dipantau/dikendalikan dari kejauhan sehingga masyarakat nyaman dalam meninggalkan rumah. Cara kerja pada sistem alat ini adalah ketika pesan pada aplikasi di android telah online maka alat akan bekerja dan membaca nilai dar firebase yang akan diproses oleh mikrokontroller, terdapat 3 reference pada firebase yang mana berfungsi untuk masing-masing alat yaitu Siaga 1 alaram, siaga 2 exhaust fan, Siaga 3 listrik dan 1 value untuk pesan komunikasi antara alat dan aplikasi pada android.

Ketika status alarm mati maka kondisi gas dalam keadaan aman dan data yang diolah oleh mikrokontroller akan diberitahukan dengan mengirim value ke firebase yang nilainya akan dibaca oleh aplikasi android, bahwa alaram mati dan gas dalam kondisi aman. Pada saat gas yang keluar melebihi kondisi aman yaitu 0-19 ppm maka alaram akan otomatis hidup menandakan siaga 1 yang 2225 berarti pengguna harus memeriksa langsung gas Lpg, sedangkan untuk siaga 2 exhaust fan akan hidup secara otomatis bila gas yang keluar sudah mencapai 27-33 ppm dan exhaust fan akan bekerja langsung untuk membuang gas yang keluar. Saat mencapai siaga 3 berati gas yang keluar melebihi 40 ppm listrik otomatis akan mati, buzzer hidup dan exhaust fan akan hidup untuk membuang gas yang keluar.

\subsection{Rancangan Program Android}

Catu daya dibutuhkan untuk mensupply rangkaian. Karena hanya mikrokontroler yang memerlukan sumber tegangan langsung, sedangkan komponen lain mengambil tegangan dari mikrokontroler.

\subsection{Perancangan Pembuatan Perangkat Kelas}

Gambar 2 merupakan rangkaian elektronika alat secara keseluruhan dengan beberapa komponen utama yang penting untuk membuat alat dapat beroperasi dimana NodeMCU V1.0 pada port D2/ground dan 3v terhubung dengan relay, port D1 terhubung dengan Buzzer, lalu pada relay channel yang terhubung pada port $\mathrm{D} 3 / 3 \mathrm{v}$ dan ground, relay yang pertamaterhubung dengan Fan DC, relay yang kedua terhubung dengan LED disetiap komponen yang dihubungkan dengan relay memiliki indikator yang berfungsi untuk mengetahui kondisi hidup atau matinya setiap komponen yang terpasang, power pada NodeMCU diberikan dengan adapter 5V DC dan power yang didapatkan pada tiap komponen yaitu 9V DC dan 1 Ampere yang akan dibagi pada 2 komponen yang terpasang.

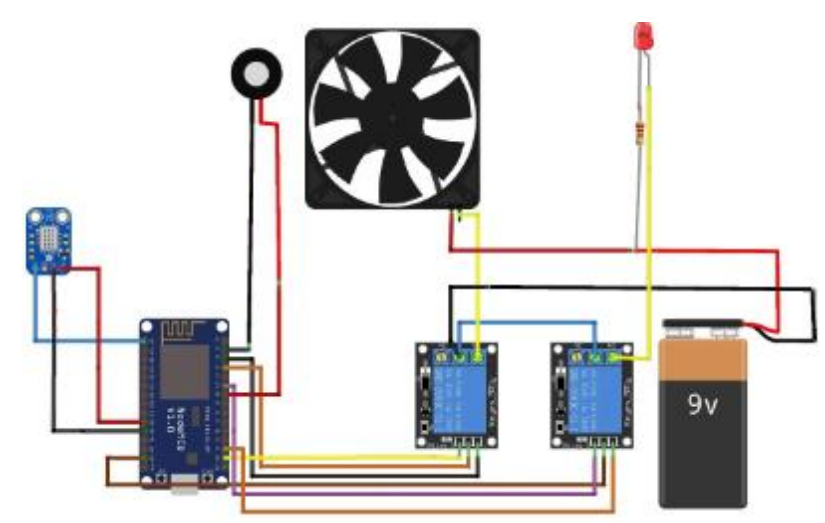

Gambar 2. Rangkaian Keseluruhan

\subsection{Pengunaan Software IDE Arduino}

Perancangan sistem pada software arduino sangatlah penting sebab dari sinilah program dibuat dan diunggah menggunakan software arduino, hal ini bertujuan untuk menyisipkan kode program kedalam arduino [11] . Berikut adalah inisialisasi program arduino menggunakan NodeMCU 1.0 seperti yang di tunjukan oleh gambar 3 .

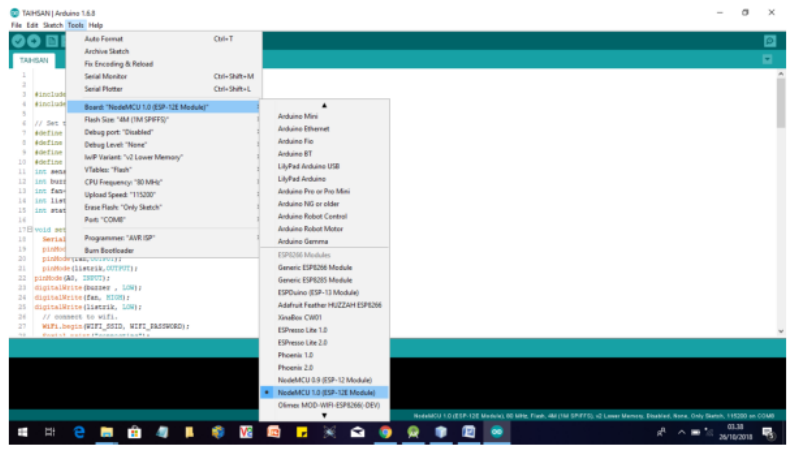

Gambar 3. Inisialisasi Program Arduino

Langkah ini bertujuan untuk memilih jenis dari mikrokontroller NodeMCU 1.0 yang akan digunakan untuk membuat sistem [12]. Pada perancangan alat ini menggunakan NodeMCU 1.0. Selain langkah di atas perlu juga diinisialkan port serial tujuannya agar NodeMCU dapat terhubung kekomputer biasanya menggunakan sebuah kabel USB agar NodeMCU dapat terhubung dengan komputer. Gambar 4 adalah contoh penginisialan port NodeMCU pada software ide arduino sebagai berikut.

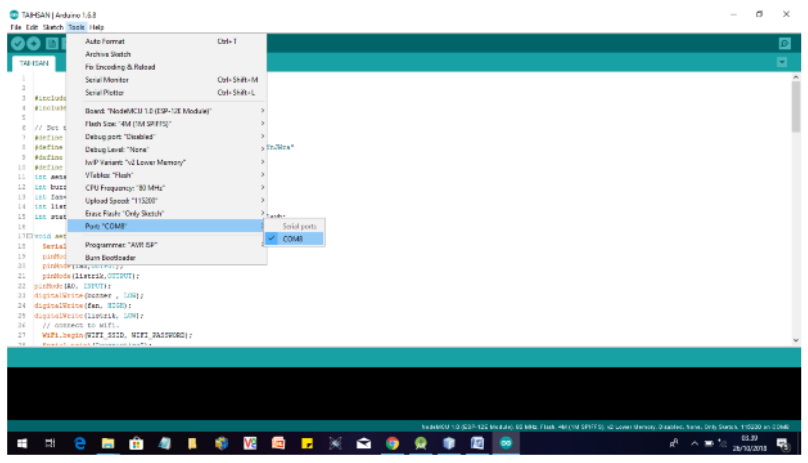

Gambar 4. Inisialisasi Port Serial NodeMCU 


\subsection{Penulisan Kode Program}

Penulisan kode program dilakukan untuk memberikan intruksi- intruksi menggunakan bahasa pemrograman $\mathrm{C}++$ yang bertujuan untuk menjalankan sistem agar dapat bekerja sesuai kode pr98ogram yang telah diisikan kedalam sebuah NodeMCU, tanpa kode program sistem tidak dapat bekerja sebab kode program adalah bagian yang paling utama dalam kita membuat sebuah alat. Gambar 5 adalah tampilan layer untuk mengisikan kode program pada software ide arduino sebagai berikut.

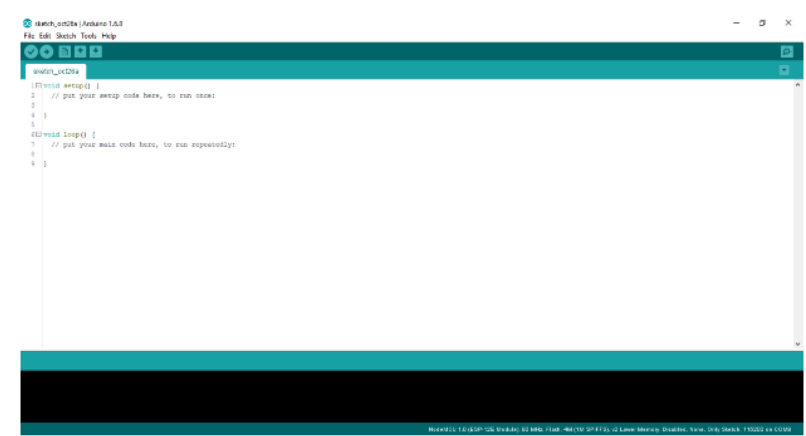

Gambar 5. Layer Penulisan Sketch Program

\subsection{Diagram Alir}

Pada diagram alir di gambar 6 ini menjelaskan tentang bagaimana cara kerja dan proses alat bekerja: Berawal dari mulai saat catu daya dihubungkan dengan mikrokontroller, lalu mulai sebuah inisialisasi awal yaitu SSID, Relay, Buzeer, exhaust fan, Led dan variabelvariabel yang digunakan. Setelah semua terkoneksi ke mikrokontroller maka langkah selanjutnya adalah melakukan penyetingan SSID dan Password apakah wifi tersedia, jika ada maka akan dilanjutkan untuk melakukan dan memeriksa koneksi ke internet, jika koneksi ke internet tersambung maka selanjutnya alat akan mengkoneksikan ke firebase server dan smartphone juga akan terkoneksi dengan firebase yang sama dengan alat yang di buat, setelah itu smartphone dapat mengetahui kondisi gas dan dapat memantau melalui smarphone android dengan mengirimkan data berupa pesan string ke dalam firebase.

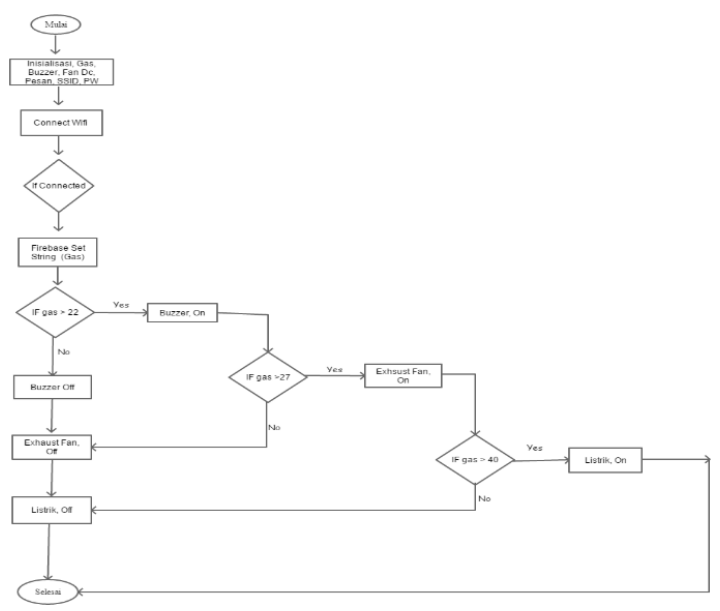

Gambar 6. Flowchart Sistem Kerja Alat

\subsection{Alat Dan Bahan}

Dalam pembuatan alat tugas akhir ini memerluhkan beberapa komponen dan bahan. Komponen dan bahan yang digunakan dalam pembuatan alat ini adalah.

\subsubsection{Alat}

1. Komponen/Laptop

Digunakan sebagai pembuat program, compile program, dan mengupload program kedalam mikrokontroller

\section{Multitester}

Multitester adalah alat ukur listrik yang dapat megukur besaran nilai komponen eletronika. Selain itu multitester juga digunakan untuk mengetahui keadaan sebuah komponen.

\section{Solder}

Solder adalah alat yang digunakan untuk menyolder terminal (kaki) komponen elektronika sehingga menyatu dengan papan rangkaian (pcb) dengan mengunakan timah atau sering disebut dengan proses menyolder (soldering process).

\section{Penyedot Timah}

Penyedot timah (atraktor) atau solder sucker merupakan peralatan yang berfungsi untuk menyedot timah yang dilelehkan dengan 4 solder ketika akan melepas komponen elektronika. Penyedot timah ini sangat berguna bagi seorang teknisi ketika akan melepas komponen yang rusak untuk diganti dengan komponen baru, karena mengingat pada umumnya komponen yang tersolder susah diangkat dengan tanpa menghilangkan terlebih dahulu timah yang merekatkannya.

\subsubsection{Bahan}

Bahan-bahan yang dibutuhkan dalam pembuatan alat ini dapat dilihat pada tabel 1 .

Tabel 1. Komponen Yang Digunakan

\begin{tabular}{|c|l|c|}
\hline No & \multicolumn{1}{|c|}{ Nama Komponen } & Jumlah \\
\hline 1 & NodeMCU V1.0 & 1 \\
\hline 2 & Fan DC & 1 \\
\hline 3 & LED & 2 \\
\hline 4 & Relay 4ch & 2 \\
\hline 5 & Buzzer aktif & 1 \\
\hline 6 & Baterai 9v & 1 \\
\hline 7 & Sensor MQ-2 & 1 \\
\hline 8 & Sterofom & Secukupnya \\
\hline 9 & Konektor Male & Secukupnya \\
\hline 10 & Kabel Data & 1 \\
\hline 11 & Resistor & Secukupnya \\
\hline 12 & Triplek & Secukupnya \\
\hline 13 & Lem Korea & Secukupnya \\
\hline 14 & Kabel Jumper & Secukupnya \\
\hline 15 & Selongsong Kabel & Secukupnya \\
\hline 16 & Kebutuhan Lainnya & Secukupnya \\
\hline
\end{tabular}

\subsection{Rancangan Program Android}

Rancangan program android adalah, rancangan yang 
akan digunakan untuk berkomunikasi dengan alat yang akan dibuat [13], berikut rancangan program yang dibuat :

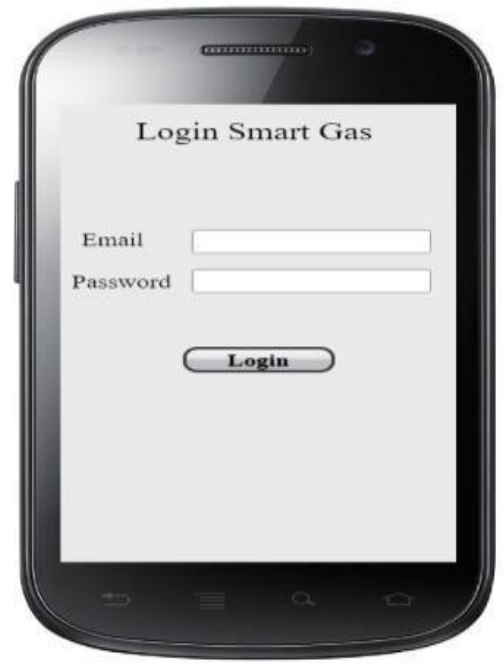

Gambar 7. Rancangan Login

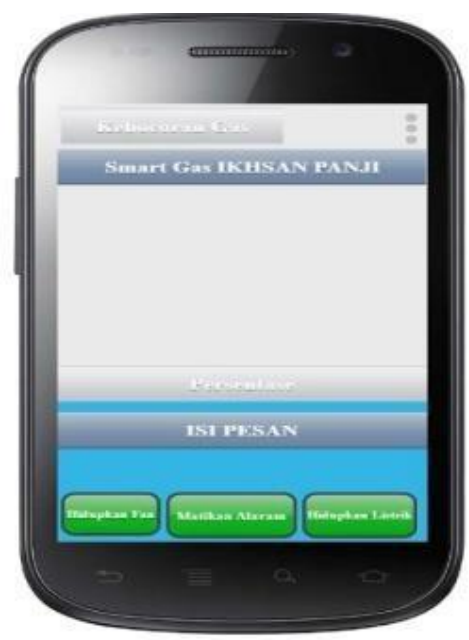

Gambar 8. Rancangan Menu Utama

\section{Implementasi dan Pengujian}

\subsection{Cara Kerja Sistem}

Sistem yang dirancang pada alat ini bekerja dengan mendeteksi gas yang keluar secara otomatis.Dalam hal ini adalah monitoring pada alat dapat dilakukan kapan pun dan dimanapun jika terdapat koneksi internet. Alat ini mempunyai aplikasi yang dimana dapat menghidupkan maupun mematikan alat pendeteksi kebocoran gas tersebut.

Cara pengoprasian alat pendeteksi kebocoran gas dilakukan dengan menggunakan aplikasi yang diprogram didalam android dan mikrokontroller yang sudah ditanami program. Jika pada alat pendeteksi kebocoran gas pada mikrokontroller dalam keadaan hidup maka program di Android akan memberi tahukan bahwa status alat pendeteksi kebocoran gas tersebut sedang menyala, begitupun sebaliknya jika alat pendeteksi kebocoran gas pada mikrokontroller mati maka program di Android juga akan memberitahu status alat tersebut dalam keadaan mati. Pada program di android juga dapat mengontrol yang mana pada progra diandroid terdapat 3 tombol gambar untuk mengontrol 3 buah elektronika yang sudah diprogram di arduino.

\subsection{Pembahasan}

Pada bagian ini akan dilakukan pembahasan hasil implementasi terhadap sistem yang telah dibuat apakah fungsi-fungsi yang telah dibuat dapat berjalan dengan baik dan benar sesuai hasil output yang diinginkan.

\subsubsection{Tampilan Sensor MQ-2}

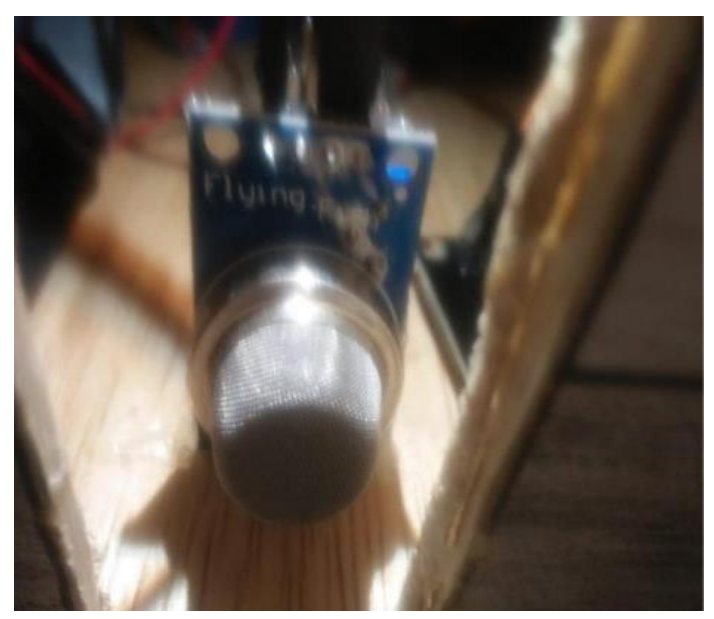

Gambar 9. Tampilan Sensor Sebagai Pendeteksi Gas LPG

Sensor terletak di bagian pintu belakang ruang dapur, alat yang terhubung pada pin 3v, Ground dan Analog di NodeMCU, berfungsi sebagai Pendeteksi Gas yang keluar.

\subsubsection{Tampilan Buzzer}

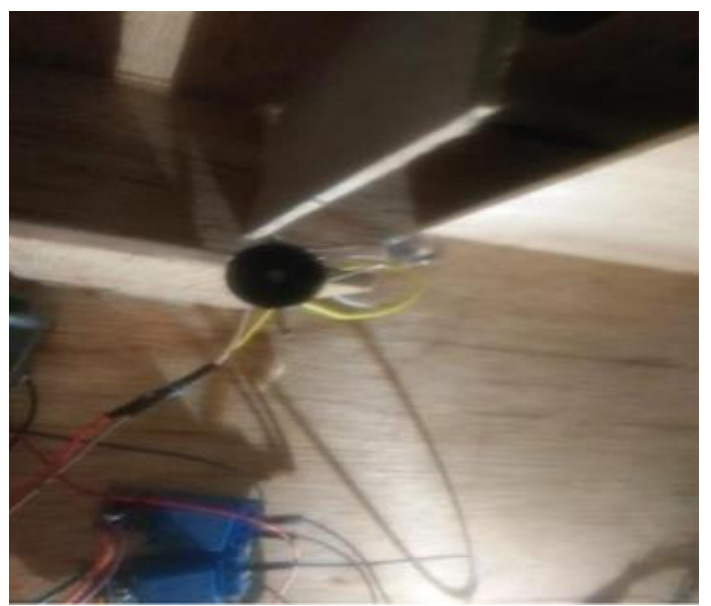

Gambar 10. Tampilan Buzzer Sebagai Simulasi Alarm

Alarm terletak di bagian atas ruang dapur, alat yang terhubung pada pin D1 dan ground di NodeMCU, berfungsi sebagai Alaram pada rumah tangga sedangkan buzzer berfungsi sebagai simulasi elektronik Alarm yang dapat mengeluarkan suara. 


\subsubsection{Tampilan Fan DC}

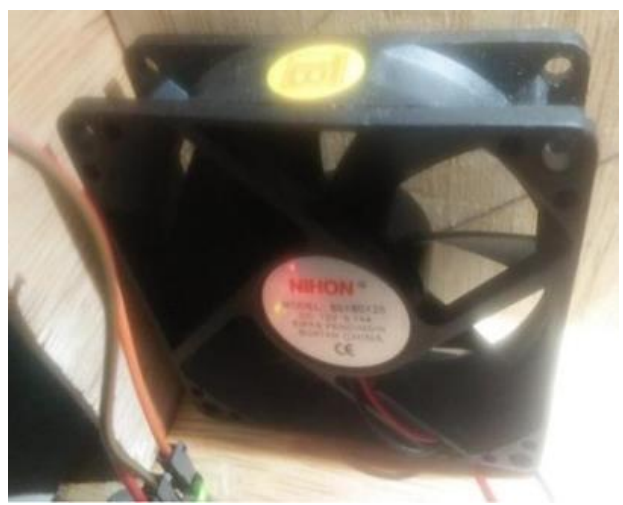

Gambar 11. Tampilan Fan DC Sebagai Pembuagan Gas

Kipas terletak pada pojok alat yang terhubung pada relay, berfungsi sebagai pembuang panas pada ruangan rumah tangga sedangakn fan Dc berfungsi sebagai simulasi alat pembuang gas yang akan keluar.

\subsubsection{Tampilan LED}

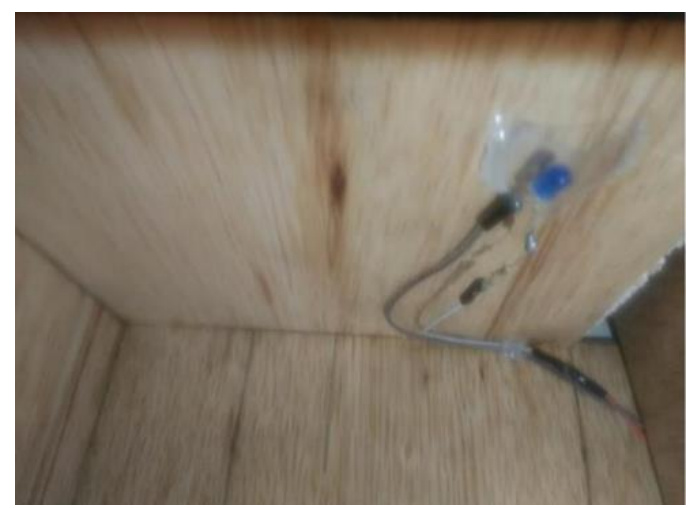

Gambar 12.. Tampilan LED Sebagai Simulasi Listrik

Listrik terletak pada bagian atas alat yang terhubung pada Relay, berfungsi sebagai Listrik pada rumah tangga sedangakn LED berfungsi sebagai simulasi pada elektronik Listrik yang dapat Menghidupkan alat rumah tangga.

\subsubsection{Tampilan Relay}

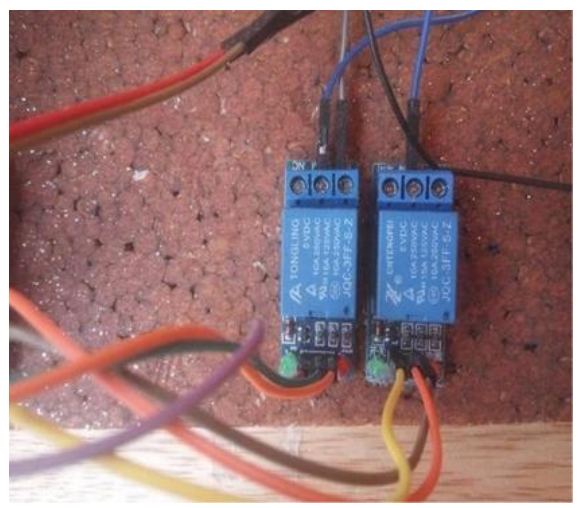

Gambar 13. Tampilan Relay Sebagai Saklar
Relay merupakan komponen yang bekerja berdasarkan elektromagnetik untuk menggerakan sejumlah kontraktor yang tersusun atau sebuah saklar elektronis yang dapat dikendalikan dari rangkaian dari rangkaian elektronik lainnya dengan memanfaatkan tenaga listrik sebagai sumber energinya. Relay berfungsi sebagai saklar elektrik untuk mengontrol elektronik alat.

\subsubsection{Tampilan Baterai}

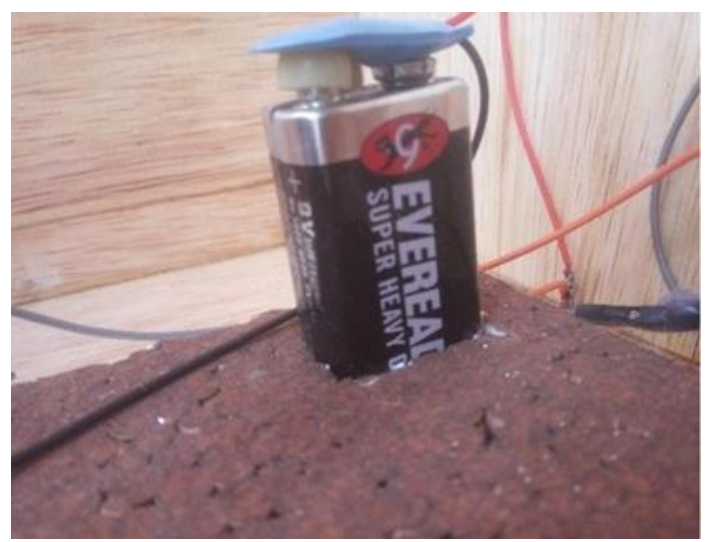

Gambar 14. Tampilan Baterai Sebagai Cadangan Daya

Baterai terletak di bagian pojok ruangan dapur, alat yang terhubung pada Relay, berfungsi sebagai Cadangan daya apabila listrik mati pada rumah.

\subsubsection{Tampilan NodeMCU}

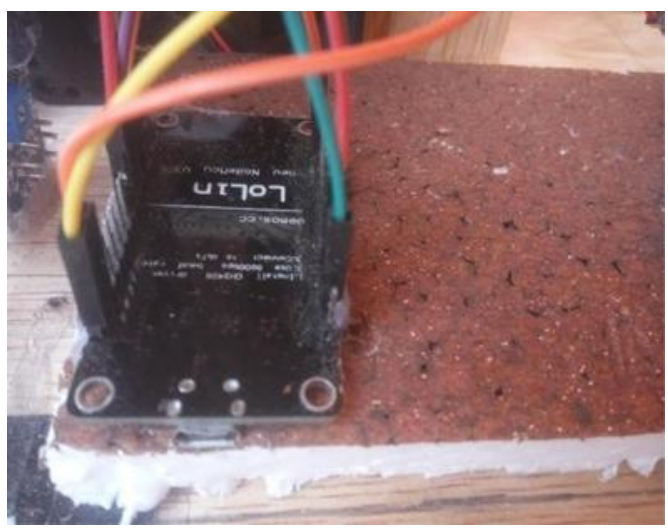

Gambar 15. Tampilan NodeMCU Sebagai Otak Pada Alat Pendeteksi Kebocoran Gas.

NodeMCU adalah sebuah platform IoT yang bersifat opensource, berfungsi sebagai mikrokontroller yang mengatur semua kinerja alat sekaligus sebagai wifi. 


\subsubsection{Tampilan Login}

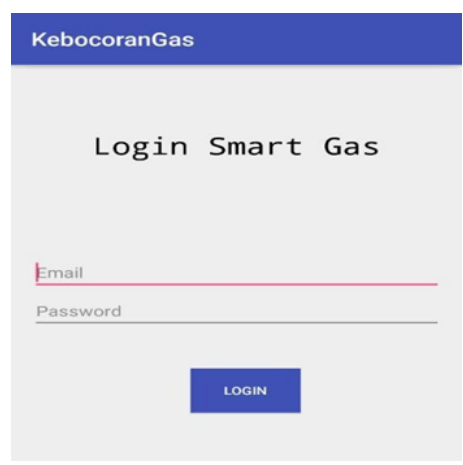

Gambar 16. Tampilan Login

Login merupakan proses yang dilakukan dengan memasukkan identitas dari akun pengguna agar pengguna dapat masuk kedalam halaman utama pada software di smartphone.

\subsubsection{Tampilan Menu Utama}

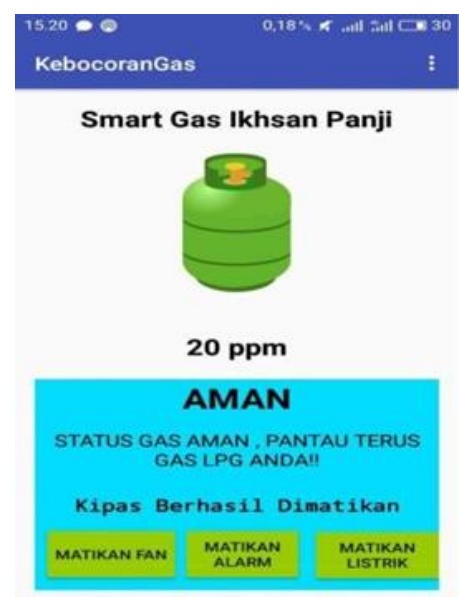

Gambar 17. Tampilan Halaman Utama

Menu Utama adalah tampilan dimana akan menampilkan menu utama yang berisikan 3 Buah ikon tombol masing masing komponen elektronika yaitu Exhaust Fan, Alaram, Listrik da nada bagian titik tiga di pojok kanan atas terdapat informasi, Tentang, dan keluar.

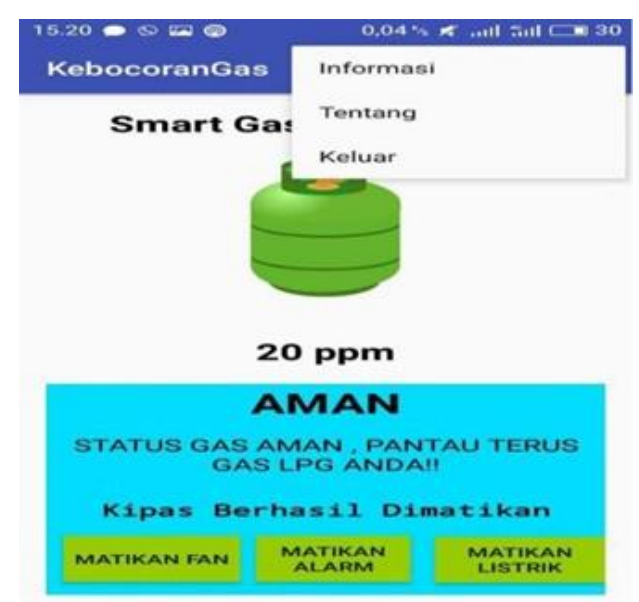

Gambar 18. Tampilan Halaman Utama

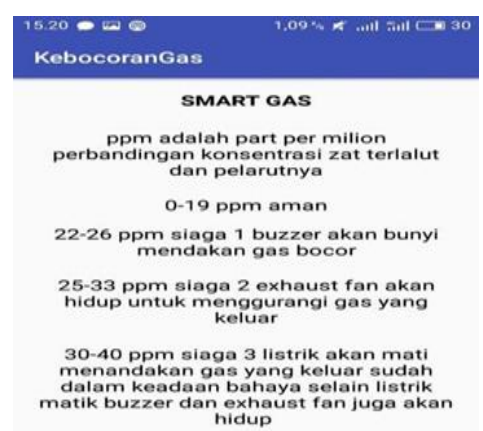

Gambar 19. Tampilan Halaman Informasi

\subsection{Pengujian}

Tujuan dari pengujian ini adalah untuk membuktikan apakah sistem yang dibuat memenuhi spesifikasi yang telah direncanakan. Hasil penguji akan dimanfaatkan untuk menyempurnakan kinerja sistem dan sekaligus digunakan dalam pengembangan lebih lanjut. Pengujian sitem ini terdiri dari beberapa tahapan, dimulai dari pengujian terhadap tiap-tiap bagian pendukung sistem hingga penguji sistem secara keseluruhan. Dari hasil pengujian maka dapat dianalisa kinerja-kinerja dari tiaptiap bagian sistem yang saling berintraksi sehingga terbentuklah Sistem Kendali Alat Elektronik Rumah Tangga menggunakan aplikasi Android. Pengujian terhadap keseluruhan sistem berguna untuk mengetahui bagaimana kinerja dan tingkat keberhasilan dari sistem tersebut.

Tahap pengujian akan dilakukan dengan urutan sebagai berikut:

1. Pengujian Relay

2. Pengujian NodeMCU 1.0

3. Pengujian Buzzer

4. Pengujian Exhaust Fan

5. Pengujian Listrik

6. Pengujian Realtime Database

7. Pengujian Keseluruhan Alat

\subsubsection{Pengujian Relay}

Pada tahap pengujian ini yang dilakukan adalah menguji kinerja dari alat ini yang menjadi sebagai saklar.Pengujian ini bertujuan untuk memastikan apakah relay dapat berkerja dengan baik dan benar, dan fungsi yang telah diprogram dapat berjalan dengan semestinya. Berikut adalah tampilan relay yang diimplementasikan pada alat dapat dilihat pada gambar 20.

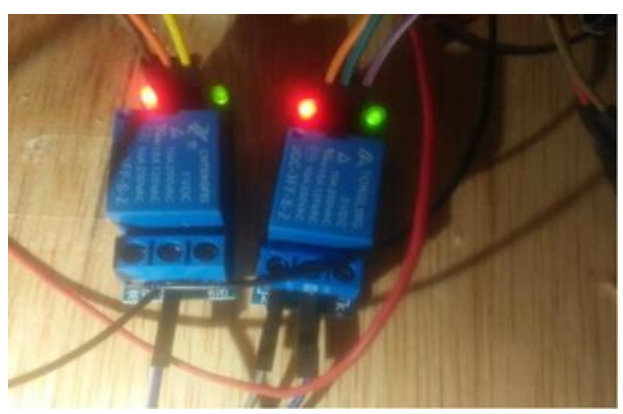

Gambar 20. Pengujian Relay 


\subsubsection{Pengujian NodeMCU 1.0}

Pada bagian ini dilakukan pengujian Mikrokontroller NodeMCU 1.0 apakah NodeMCU 1.0 dapat berkerja dengan baik seperti memproses data digital yang diinginkan, lalu dapat mengkoneksikan kedalam wifi yang diinginkan serta mampu terkoneksi dengan server firebase berikut adalah hasil pengujian dari NodeMCU 1.0.

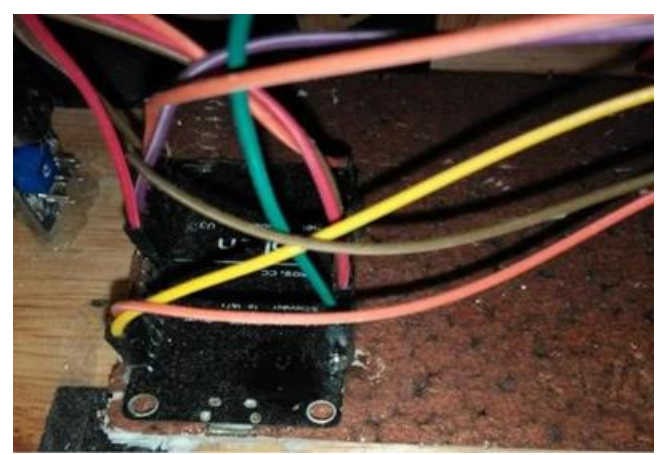

Gambar 21. Pengujian NodeMCU 1.0

\subsubsection{Pengujian Buzzer}

Pengujian yang dilakukan pada tahap ini yaitu bertujuan untuk apakah Buzzer yang dihubungkan dengan relay pada NodeMCU 1.0 dapat berkerja dengan baik seperti dapat mematikan atau menghidupkan lampu dari android, berikut hasil pengujian pada arduino.

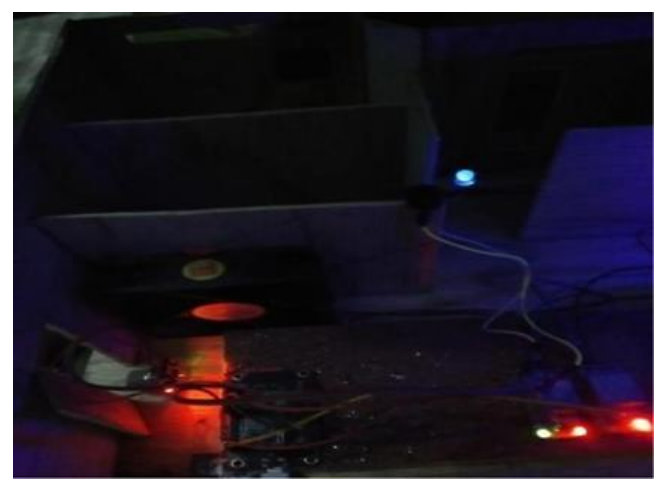

Gambar 22. Buzzer Hidup

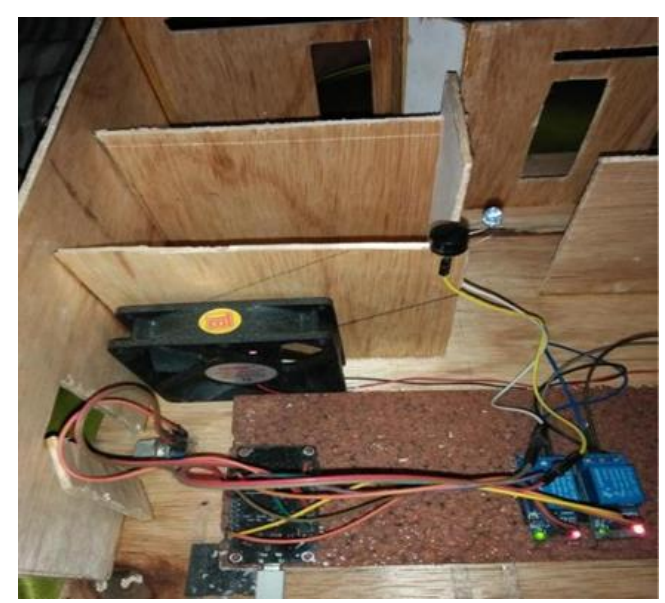

Gambar 23. Buzzer Mati

\subsubsection{Pengujian Exhaust Fan}

Pengujian yang dilakukan pada tahap ini yaitu bertujuan untuk apakah fan yang dihubungkan dengan relay pada NodeMCU 1.0 dapat berkerja dengan baik seperti dapat mematikan atau menghidupkan listrik dari android, berikut hasil pengujian pada arduino.

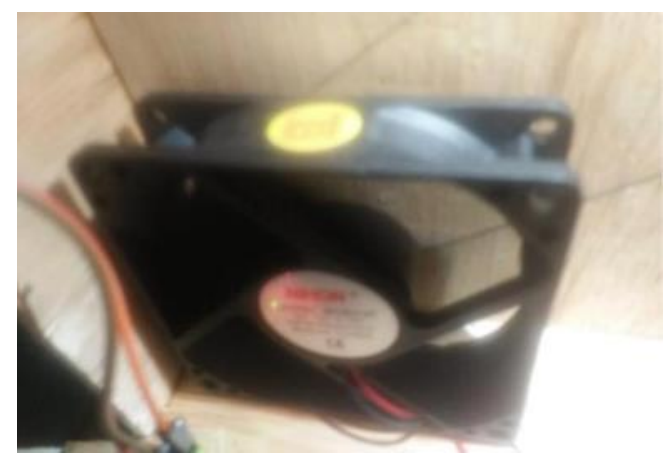

Gambar 24. Exhaust Fan Hidup

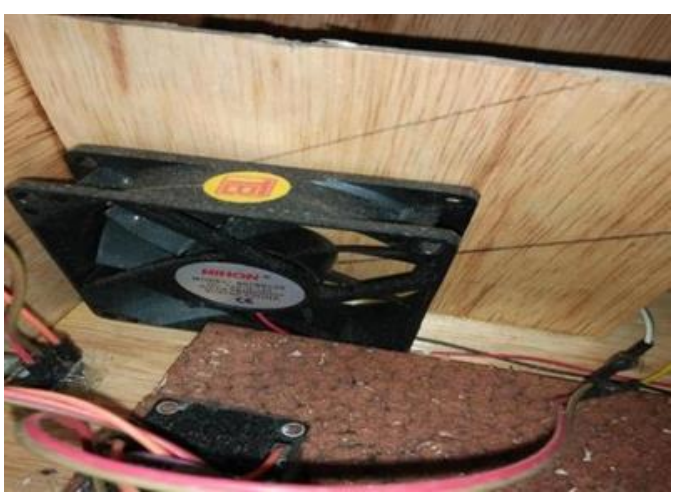

Gambar 25. Exhaust Fan mati

\subsubsection{Pengujian Listrik}

Pengujian yang dilakukan pada tahap ini yaitu bertujuan untuk apakah listrik yang dihubungkan dengan relay pada NodeMCU 1.0 dapat berkerja dengan baik seperti dapat mematikan atau menghidupkan listrik dari android, berikut hasil pengujian pada arduino.

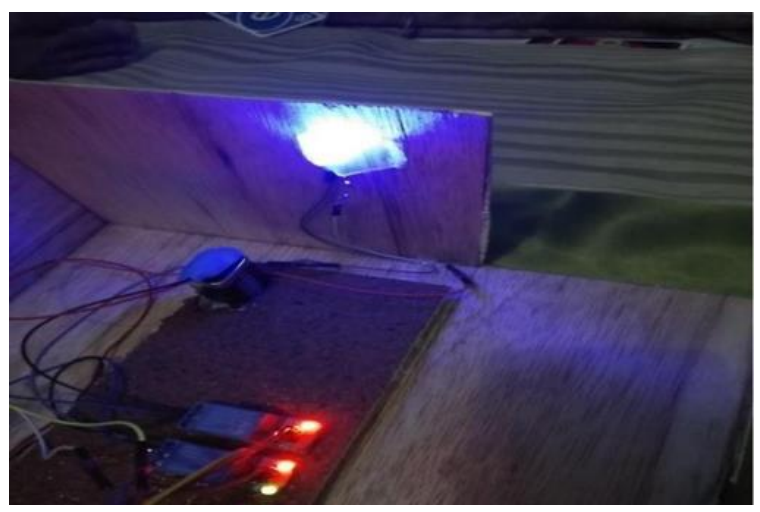

Gambar 26. Listrik Hidup 


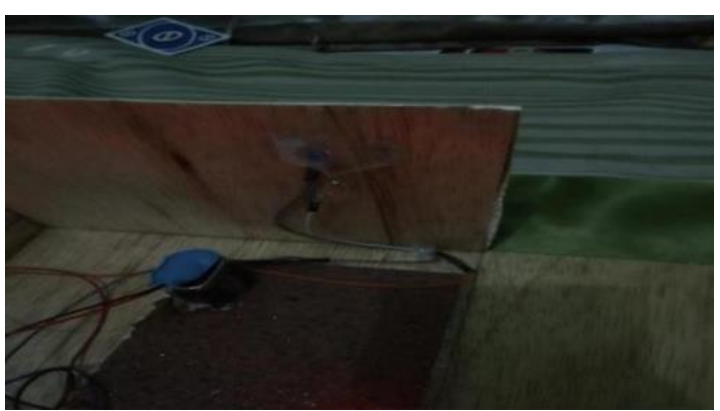

Gambar 27. Listrik Mati

\subsubsection{Pengujian Relatime Database}

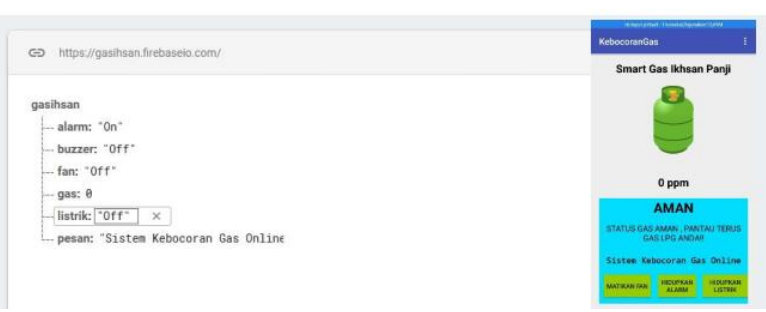

Gambar 28. Pengujian Realtime Database

\subsubsection{Pengujian Keseluruhan Alat}

Pengujian yang dilakukan pada tahap ini bertujuan untuk apakah Komponen Komponen yang terdapat pada Alat rumah tangga dapat terhubung dengan baik dan berkerja sesuai dengan yang di perintahkan.

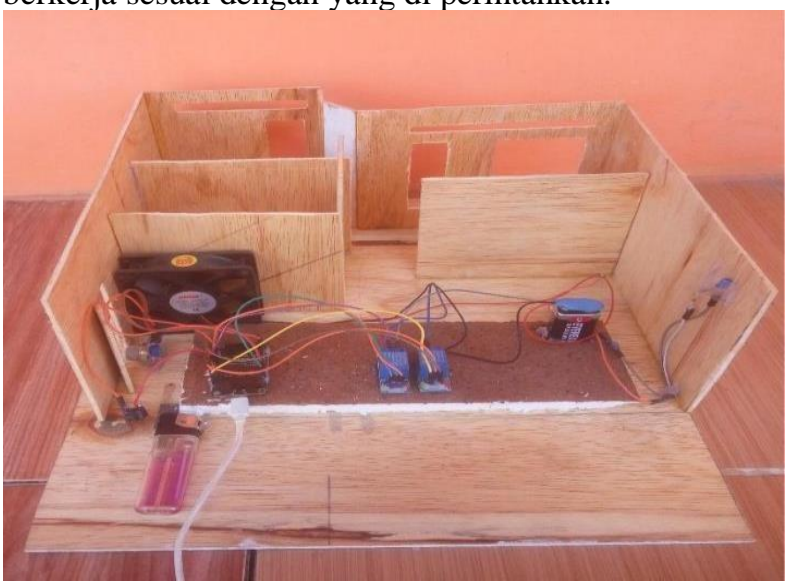

Gambar 29. Pengujian Keseluruhan Alat

Gambar miniature keseluruhan alat yang digunakan untuk implementasi pendeteksi kebocoran gas pada perangkat mobile android dengan sensor mq-2, Korek api yang terdapat pada gambar 4.22 digunakan sebagai simulasi gas LPG.

\section{Kesimpulan dan Saran}

\subsection{Kesimpulan}

Berdasarkan hasil penelitian dan pembahasan maka dapat disimpulkan sebagai berikut.

1. NodeMCU dan Smartphone dapat terhubung dan terkoneksi dengan baik ke firebase apabila tidak terjadi gangguan koneksi internet.
2. Relay dapat berfungsi dengan baik saat digunakan sebagai saklar untuk menghidupkan dan mematikan komponen yang ingin dinyalakan atau dimatikan melalui aplikasi android.

3. Aplikasi Android dengan IoT Smart Gas dapat berjalan dengan baik di Smartphone sistem operasi android versi lolipop dan marshmallow.

\subsection{Saran}

Berdasarkan perancangan dan hasil implementasi program yang dilakukan maka saran yang perlu diperhatikan dalam pengembangan sistem ini adalah sebagai berikut.

1. Penambahan lupa password dibagian login agar dapat ditangani bila pengguna tidak ingat dengan password nya.

2. Perlu penggantian Sensor yang berkualitas lebih tinggi karena sensor MQ-2 memerlukan waktu beberapa saat untuk membuat sensor bekerja

3. Agar dapat menambahkan penanganan berupa fire sprinklers alat yang digunakan untuk memadamkan api secara otomatis dan alat ini merupakan bagian dari fire sprinkler system yang akan mengeluarkan debit air ketika terdeteksi adanya api / telah melampaui suhu yang ditentukan.

\section{Daftar Pustaka}

[1] Budi Tjahjono dkk. 2013. Perancangan Deteksi Kebocoran Tabung Gas Berbasis Mikrokontroler AT89S52.

[2] A. Nurkholis, A. Riyantomo dan M. Tafrikan, "Sistem pakar penyakit lambung menggunakan metode forward chaining," Majalah Ilmiah Momentum, vol. 13, no. 1, 2017.

[3] A. Nurkholis, dan I. S. Sitanggang, "Optimalisasi model prediksi kesesuaian lahan kelapa sawit menggunakan algoritme pohon keputusan spasial," Jurnal Teknologi dan Sistem Komputer, vol. 8, no. 3, pp. 192-200, Jul. 2020.

[4] Erlansyah And Widyanto.,2014, Alat Deteksi Kebocoran Tabung Gas Elpiji Berbasis MIkrokontroler. Dosen Universitas Bina Darma Palembang

[5] Iksal dkk, 2016 Rancang Bangun Prototype Dini Dan Pendeteksi Kebocoran Gas LPG Berbasis Mikrokontroler Melalui Sms., Program Studi Sistem Komputer, Universitas Serang Raya.

[6] R.I. Borman, K. Syahputra dan P. Prasetyawan, "Implementasi Internet Of Things pada Aplikasi Monitoring Kereta Api dengan Geolocation Information System," Seminar Nasional Teknik Elektro, pp. 322-327, 2018.

[7] D. Alita, S. Priyanta dan N Rokhmn., "Analysis Emoticon and Sarcasm Effect on Sentiment Analysis of Indonesian Language in Twitter”,JISEBI, 2019.

[8] K. Pindrayana, R.I. Borman, B. Prasetyo dan S. Samsugi, "Prototipe Pemandu Parkir Mobil Dengan 
Output Suara Manusia Mengunakan Mikrokontroler Arduino Uno," CIRCUIT: Jurnal Ilmiah Pendidikan Teknik Elektro, vol. 2, no. 2, 2018.

[9] S. Samsugi dan A. Burlian, "Sistem penjadwalan pompa air otomatis pada aquaponik menggunakan mikrokontrol Arduino UNO R3,". Prosiding Semnastek, vol. 1, no. 1, 2019. Yozi Yozandra. 2017. Rancang Bangun Alat Pendeteksi Kebocoran Gas Mengunakan Arduino dan Notifikasi.

[10] I. K. Gunawan, A. Nurkholis dan A. Sucipto, "Sistem monitoring kelembaban gabah padi berbasis Arduino," Jurnal Teknik dan Sistem Komputer, vol. 1, no. 1, pp. 1-7, 2020.

[11] S. Samsugi, "Internet of Things (iot): Sistem Kendali jarak jauh berbasis Arduino dan Modul wifi
Esp8266," Prosiding Nasional Rekayasa Teknologi Industri dan Informasi XII, 2017.

[12] S. Samsugi dan D.E. Silaban, "Purwarupa Controlling Box Pembersih Wortel Dengan Mikrokontroler," Prosiding Nasional Rekayasa Teknologi Industri dan Informasi XIII, pp. 1-7, 2018.

[13] D.E. Kurniawan, M. Iqbal, J. Friadi, R.I. Borman dan R. Rinaldi. "Smart Monitoring Temperature and Humidity of the Room Server Using Raspberry Pi and Whatsapp Notifications," In Journal of Physics: Conference Series (Vol. 1351, No. 1, p. 012006) IOP Publishing, 2019. 